\title{
Transmissão e obtenção de informação em saúde
}

\author{
Health transmission and obtaining of information
}

Vitor M anuel Costa Pereira Rodrigues ${ }^{1}$

${ }^{1}$ ESEnfVR/CIDESD, Universidadede Trás-os-M ontes e Alto Douro. Lugar do Tojal, Lordelo, 5000. Vila Real Portugal.vmcpr@utad.pt
Abstract By identifying the resulting benefits of the application of a information program (constituted by pamphlets accompanied by verbal information), either in the change of the nurses behaviour to the transmission of information, or in the obtaining of the same by the patients, it was possible to develop a systematized knowledge that allowed to clarify the nurses role in the hospital internment, and that the specified in the letter of the rights and duties of the patient could be respected. The aims of this study are to identify how the application of an information program produces changes in the nurses' behaviour in transmitting the information, and to verify the effectiveness of the introduction of a information program re garding the information obtaining on the part of the patients. It was an experimental study and the populations that were in the base of this study were composed by patients interned in medicine services and surgery services and for nurses that exercise its profession in medicine services and in surgery services. We conclude that the share attitude of information is higher in nurses of the group submitted to an information program comparing to the ones who were not. Similarly, patients of the group submitted to a information program obtained more information.

Key words Information program, Patients, Nurses, Communication
Resumo Ao identificar os benefícios resultantes da aplicação de um programa deinformação ( constituído por fol hetos escritos e acompanhado por informações verbais), quer na mudança de comportamento dosenfermeiros relativamenteà transmissão deinformações, quer na obtenção das mesmas por partedos doentes, foi possível desenvolver um conhecimento sistematizado que permitiu clarificar o papel dos enfermei ros no internamento hospitalar. Este estudo teve como objectivos identificar de que forma a aplicação de um programa de informação produz alterações no comportamento dos enfermeiros relativamente à transmissão de informações e verificar a eficácia da introdução de um programa de informação no que diz respeito à obtenção de informações por parte dos doentes. Tratou-sedeum estudo quase experimental e as populações que estiveram na base deste estudo são compostas por doentes internados em serviços de medicina e serviços de cirurgia e por enfermei ros que exercem a sua profissão em serviços de medicina e em serviços de cirurgia. A partilha de informação é maior em enfermeiros do grupo submetido a um programa de informação do que em enfermeiros do grupo não submetido ao programa; os doentes do grupo submetido a um programa de informação obtêm mais informações do que os doentes do grupo que não foi submetido ao programa.

Palavras-chave Programa de informação, Doentes, Enfermeiros, Comunicação 
Introdução

A comunicação assume um papel fundamental no estabelecimento de uma relação interpessoal. Sempre que duas ou mais pessoas se encontram, estabel ece-se entre elas al gum tipo de comunicação, visto que o próprio comportamento é comunicativo ${ }^{1}$.

$\mathrm{Na}$ enfermagem, a comunicação ultrapassa o relacionamento entre o enfermeiro eo doente, para se envolver em termos de cooperação e coordenação com todos os elementos da equipe de saúde.

Para todos aqueles que desenvolvem a sua actividade profissional junto de doentes, não constitui novidade o facto de inúmeros factores psicológicos e sociais, ligados ao doente, desempenharem um papel muito importante e por ve zes decisivo, não só no aparecimento da doença, como também na sua evolução e prognóstico.

É frequentemente visível, nos doentes, sinais de grande tensão e ansiedade, denotando medo do desconhecido, dos tratamentos e dos meios auxiliares de diagnóstico que possam vir a reali$z^{2}{ }^{2}$. Perante esta situação, para além dos doentes esuas famílias, os enfermeiros er restanteequipa não se sentem muitas vezes bem e à vontade para intervir. Resulta um ambiente que em nada ajuda o doente. É notório quenão estão suficientemente informados da situação que vão experimentar e essa ignorância é em grande parte responsável pelos níveis el evados de ansiedade que possam apresentar ${ }^{3}$.

M essner ${ }^{4}$ refere que um dos aspectos que os doentes apreciam na prestação dos cuidados de enfermagem são as informações explicações que os enfermeiros Ihes vão fornecendo, pois ajudam a passar por acontecimentos que desconheciam.

0 ambiente hospitalar pode reforçar a impressão de despersonalização. Com grande fre quência, muitos profissionais solicitam informações excessivas, de tal modo que os doentes podem sentir-se exaustos e extremamente confusos com o que se passa. Os doentes referem que 0 pessoal é amável mas compreendem que estão muito atarefados e têm pouco tempo. Pesquisas feitas nos últimos anos demonstram que há uma variada proporção de utentes que se consideram insatisfeitos com a informação que Ihes foi prestada, tendo sido detectados muitos problemas e queixas, devidos à informação reduzida ou incompreensível sobre tratamentos e cuidados a prestar $^{5-10}$.

De acordo com Pio Abreu ${ }^{11}$, adquirir informação édispor dela em permanência. Seja qual for o processo de aquisição, o ente informado (ou antes, enformado) torna-se mais complexo, os seus elementos diferenciam-se e organizam-se melhor, existindo uma evolução neguentrópica. Esta ideia é aquela que está de acordo com o sentido de informação de Aristóteles, que é o de enformação, como acontece no caso de uma estátua de bronze, que só representará uma figura humana se for devidamente moldada. No organismo humano, o processo de construção tem a ver com 0 processo embriológico (informação dada pelos genes) e pela educação e o meio onde está inserido, conseguindo-se resultados após grande dispêndio energético do emissor.

0 acto passageiro de transmitir uma informação pertenceao domínio do tempo. Pio Abreu ${ }^{11}$ refere a este propósito: um sinal esgota-se por si se não apoiar o seu sentido nos sinais que o precedem ou sucedem, ou seja, senão formar um padrão componente deum paradigma euma estrutura dotada de sintaxee, para além disso, se 0 acto informativo não produzir qualquer efeito no destinatário (receptor), essa informação perde-se.

Deste facto, resulta que a informação não pode desligar-se do seu significado e só é válida se produzir efeitos no receptor. Mas, para que isso aconteça, o receptor tem de estar preparado para poder responder com eficácia à informação transmitida. Pode-se então dizer que existe informação significativa quando os custos energé ticos da transmissão de uma mensagem forem menores que os custos energéticos da mudança operada no receptor que determinou o significado da mensagem ${ }^{12}$.

0 transmitir informação não excessivamente exaustiva, mas ajustada às necessidades de cada doente, poderá constituir a estratégia mais adequada para reduzir o mais possível a ansiedadee o medo do desconhecido. Doentes com conhecimentos adequados e suficientes estariam menos ansiosos, o medo do desconhecido seria diminuído e a sua colaboração durante todo o tratamento seria mais eficaz.

É difícil dar a informação adequada sem perguntar às pessoas o que pretendem saber etentar compreender o seu ponto de vista. Relativamente aos doentes recém-hospitalizados, é muito importante usar a comunicação aberta, sendo 0 estabelecimento de uma relação condição prévia essencial à troca de informações. Os doentes necessitam de orientação quanto à geografia do serviço deinternamento, designadamente da zona sanitária e dos nomes das pessoas que vão cuidar deles. Se o enfermeiro que os receber semostrar interessado em saber quais as reacções ao 
internamento e principais preocupações, sentirse ão mais apoiados e haverá partilha de informação adequada ${ }^{13}$. N esta altura, será, provavelmente, muito apreciada uma informação sobre a cronologia das ocorrências que se prevêem. Como al gumas das informações serão certamente esquecidas pelo doente, que está ansioso, será uma boa ajuda fornecer folhetos escritos com as informações mais pertinentes. É importante compreender que, para a maior parte dos doentes, os primeiros dias no hospital são de marcada ansiedade, pelo que necessitam que a informação seja repetida.

Também esta primei ra familiarização com os profissionais pode criar no doente uma impressão duradora sobre as suas atitudes e prioridades. Rodrigues ${ }^{10}$ refere que as primeiras impressões são as que mais perduram eé "no momento da admissão que o doente se sente mais inseguro e desprotegido". É importante transmitir a sensação de que se pretende responder a quaisquer perguntas sempre que elas sejam colocadas.

Perante este quadro, algumas questões foram levantadas:

- que acontecerá se os doentes que estão internados forem submetidos a um programa de informação sistematizado ?;

- que oportunidades têm os doentes de verbalizar as suas preocupações e esclarecer as suas dúvidas?;

. com um programa de informação instituído, será que os enfermeiros preocupam-se em transmitir as informações necessárias ?

0 estudo tem como objectivos identificar de que forma um programa de informação produz alterações no comportamento dos enfermeiros relativamente à transmissão de informações e conhecer o grau deobtenção de informações por parte dos doentes.

As hipóteses de investigação que foram formuladas, são as seguintes: (1) a atitude de partiIha de informação é maior em enfermeiros submetidos a um programa de informação do que no grupo de enfermeiros não submetidos ao programa; (2) os doentes do grupo submetido a um programa de informação colocam mais questões do que os doentes do grupo que não foi submetido ao programa; (3) os doentes do grupo submetido a um programa de informação obtêm mais informações do que os doentes do grupo que não foi submetido ao programa; (4) existe desfasamento entre enfermeiros e doentes no que respeita à informação transmitida e recebida.

\section{M étodos}

De acordo com os objectivos propostos, o autor orientou o estudo para uma pesquisa do tipo quase experimental14, o que permite verificar se da aplicação experimental de um programa de suporte e informação resultam, por um lado, alterações no comportamento dos enfermeiros relativamente à transmissão de informações e, por outro, verificar a obtenção das mesmas informações por parte dos doentes.

0 estudo foi concretizado no ano de 2000, em dois hospitais distritais, pertencentes à mesma região (região do Douro - Portugal) e com características idênticas, tendo sido os grupos constituídos da seguinte forma: doentes de dois hospitais distritais e enfermeiros de dois hospitais distritais, onde se obtiveram dois grupos: Experimental (doentes e enfermeiros) e controle (doentes e enfermeiros).

A impossibilidade da aleatoriedadelevou-nos a optar pela técnica de amostragem por conveniência, tendo sido seleccionados para os dois grupos: enfermeiros dos serviços de medicina e cirurgia $(20+20)$ e doentes dos serviços de medicina ecirurgia $(40+40)$.

As populações que estiveram na base deste estudo são compostas por doentes internados em serviços de medicina e serviços de cirurgia (80) e por enfermeiros que exercem a sua profissão em serviços de medicina e em serviços de cirurgia (40).

Tendo em mente o tipo de estudo pretendido (quase experimental) houve necessidade de obter dois grupos ${ }^{15}$ : grupo submetido a programa de informação (de doentes e enfermeiros) - grupo experimental; grupo não submetido a programa de informação (de doentes e enfermeiros) - grupo de controle.

As selecções das amostras foram obtidas por métodos de amostragem dirigida (não probabilistica), mais concretamente através da amostragem por conveniência ${ }^{16}$.

No presente estudo, considerámos três tipos de variáveis, apresentadas a seguir.

\section{Variável independente}

Existência de um programa de informação. A variável independente assumiu o aspecto de intervenção, por nós manipulada, junto dos enfermeiros e doentes do grupo submetido ao programa de informação (grupo experimental), no sentido de produzir as alterações previsíveis nas variáveis dependentes. Esta intervenção baseou- 
se na distribuição de um programa de informação (constituído por folhetos escritos) por parte dos enfermeiros aos doentes internados nas unidades de medicina e cirurgia do hospital onde pertencem os grupos experimentais em estudo. A distribuição destes folhetos era acompanhada com informações verbais, dado existirem doentes que não sabiam ler.

0 ambienteescolhido para a distribuição dos folhetos, assim como para a sua explicação, foi sempre junto do leito, com o doente sentado (sempre que possível) em posição confortável e com contacto visual com o enfermeiro. 0 programa deinformação, como anteriormentejá foi referido, constou essencialmente de dois aspectos: manual de acolhimento do doente, distribuído pelos enfermeiros a todos os doentes internados nas diversas unidades; avaliação da qualidade dos serviços prestados na óptica do utente utilizador, através de um questionário distribuído a todos os doentes. Acresce aqui dizer que o programa de informação introduzido e aplicado foi construído por nós.

Variáveis dependentes

Relativamente aos enfermeiros

Aspectos relacionados com a transmissão de informações:

- Informação ao doente sobre: terapêutica prescrita; tratamentos a que vai ser submetido; meios de diagnóstico a que vai ser submetido; nome do enfermeiro responsável pelo doente; nome do médico responsável pelo doente; horário e número de visitas; uso de objectos pessoais; forma de comunicar com a família e amigos; faz a entrega do manual de acolhimento; data provável da alta clínica; necessidade de manuten ção e vigilância da saúde; forma de garantir a continuidade dos cuidados no domicílio;

- Questões colocadas pelo doente acerca de: assuntos relativos ao seu tratamento; aspectos referentes ao seu internamento; aspectos relativos à alta clínica.

Relativamente aos doentes

Aspectos relacionados com a obtenção deinformações:

- Obtenção de informações relativamente a: terapêutica que estáa efectuar; tratamentos a que foi e/ou vai ser submetido; meios de diagnóstico a quefoi e/ou vai ser submetido; nome do enfer- meiro responsável por si; nome do médico responsável por si; horário e número de visitas; uso de objectos pessoais; forma de comunicar com a família e amigos; recebeu o manual de acolhimento; data provável da alta clínica; necessidade de manutenção e vigilância da saúde; forma de garantir a continuidade dos cuidados no domicílio; modo como as informações foram transmitidas;

- Colocou questões aos enfermeiros acerca de: assuntos relativos ao seu tratamento; aspectos referentes ao seu internamento; aspectos relativos à alta clínica.

\section{Variáveis atributo}

Relativamente aos enfermeiros

Sexo;

- Idade;

. Experiência profissional (tempo deserviço);

- Categoria profissional;

. Escola onde obteve a formação inicial.

Relativamente aos doentes

. Sexo;

- Idade;

- Residência;

- Habilitações literárias;

- Ocupação profissional;

. Tempo de internamento.

Antes de iniciarmoso nosso estudo, foi oficializado o pedido por escrito aos conselhos de administração das duas instituições hospitalares. Os pedidos para a realização do estudo foram aceites e autorizados por escrito.

Em termos de procedimentos éticos, os enfermeiros chefes das diversas unidades das duas instituições hospitalares foram informados acerca da realização do estudo e dos seus objectivos, garantindo a confidencialidade dos resultados e 0 anonimato dos respondentes.

Relativamenteaos procedimentos éticosjunto dos doentes, e após a minha apresentação, informei os doentes dos objectivos do estudo que estava a realizar, informei-os que os dados recoIhidos eram confidenciais e que era garantido 0 seu anonimato (até porque em nenhuma circunstância se faria referência ao nome) e que poderiam, naturalmente, recusar participar no estudo. Todos os doentes abordados acederam em colaborar no estudo. 


\section{Resultados}

\section{Transmissão de informações}

Analisando ambas as populações dos enfermeiros, conforme expresso na Tabela 1, relativamente à transmissão de informações, e dando resposta à hipótese de investigação "a atitude de partilha de informação é maior em enfermeiros do grupo submetido a um programa de informação do queem enfermeiros do grupo não submetido a um programa de informação", verificou-se (com um nível de confiança de $95 \%$ eum grau de liberdade) que, em relação aos aspectos terapêutica prescrita; tratamentos; meios de diagnóstico a que vai ser submetido; nome do enfermeiro responsável pelo doente; horário e número de visitas; uso de objectos pessoais; forma decomunicar com a família e amigos; necessidade de manutenção da vigilância de saúde eforma de garantir a continuidade dos cuidados no domicílio, existe uma relação entre os grupos estudados, confirmando-se que os enfermeiros do grupo submetido a um programa de informação transmitem mais informações do que os en- fermeiros do grupo não submetido a um programa de informação.

No que diz respeito a nome do médico responsável pelo doente e data provável da alta clínica, não se confirmou a relação entre os grupos estudados, ou seja, não se verificaram diferenças quanto à transmissão de informações entre os enfermeiros do grupo submetido a programa de informação e os enfermeiros do grupo não submetido a programa de informação.

Obtenção de informações

A análise das populações dos doentes, quanto à obtenção de informações tendo em mente a hipótese de investigação "os doentes do grupo submetido a um programa de informação obtêm mais informações do que os doentes do grupo que não foi submetido ao programa de informação", revelou que (com um nível de confiança de $95 \%$ e um grau deliberdade), econformea Tabela 2 , a respeito deterapêutica que está a efectuar; tratamentos a quefoi e/ou vai ser submetido; meios de diagnóstico a que foi e/ou vai ser submetido; nomedo enfermeiro responsável por

Tabela 1. Distribuição das populações no que respeita à transmissão de informações.

\begin{tabular}{|c|c|c|c|c|c|}
\hline $\begin{array}{l}\text { No que } \\
\text { respeita a: }\end{array}$ & $\begin{array}{l}\text { Transmissão de } \\
\text { informações }\end{array}$ & $\begin{array}{c}\text { Grupo submetido } \\
\text { a programa de } \\
\text { informação }\end{array}$ & $\begin{array}{c}\text { Grupo não submetido } \\
\text { a programa de } \\
\text { informação }\end{array}$ & $\chi^{2}$ & $\mathrm{P}$ \\
\hline \multirow[t]{2}{*}{ Terapêutica } & Quase sempre/sempre & $32(80 \%)$ & $14(35 \%)$ & 16,573 & 0,000 \\
\hline & Nunca/raramente & $8(20 \%)$ & $26(65 \%)$ & & \\
\hline \multirow[t]{2}{*}{ Tratamentos } & Quase sempre/sempre & $34(85 \%)$ & $23(57 \%)$ & 7,384 & 0,007 \\
\hline & Nunca/raramente & $6(15 \%)$ & $17(43 \%)$ & & \\
\hline \multirow[t]{2}{*}{ Meios de diagnóstico } & Quase sempre/sempre & $33(82 \%)$ & $18(49 \%)$ & 12,170 & 0,000 \\
\hline & Nunca/raramente & $7(18 \%)$ & $22(55 \%)$ & & \\
\hline \multirow[t]{2}{*}{ Nome do enfermeiro } & Quase sempre/sempre & $34(85 \%)$ & $19(47 \%)$ & 12,579 & 0,000 \\
\hline & Nunca/raramente & $6(15 \%)$ & $21(53 \%)$ & & \\
\hline \multirow[t]{2}{*}{ Nome do médico } & Quase sempre/sempre & $33(82 \%)$ & $30(75 \%)$ & 0,672 & 0,412 \\
\hline & Nunca/raramente & $7(18 \%)$ & $10(25 \%)$ & & \\
\hline \multirow[t]{2}{*}{ Horário e número de visitas } & Quase sempre/sempre & $34(85 \%)$ & $17(43 \%)$ & 15,632 & 0,000 \\
\hline & Nunca/raramente & $6(15 \%)$ & $23(57 \%)$ & & \\
\hline \multirow[t]{2}{*}{ Uso de objectos pessoais } & Quase sempre/sempre & $33(82 \%)$ & $22(18 \%)$ & 7,040 & 0,008 \\
\hline & Nunca/raramente & $7(18 \%)$ & $18(45 \%)$ & & \\
\hline \multirow{2}{*}{$\begin{array}{l}\text { Comunicar com a família } \\
\text { e amigos }\end{array}$} & Quase sempre/sempre & $34(85 \%)$ & $22(55 \%)$ & 8,571 & 0,003 \\
\hline & Nunca/raramente & $6(15 \%)$ & $18(45 \%)$ & & \\
\hline \multirow[t]{2}{*}{ Data provável da alta clínica } & Quase sempre/sempre & $18(45 \%)$ & $15(37 \%)$ & 0,464 & 0,496 \\
\hline & Nunca/raramente & $22(55 \%)$ & $25(63 \%)$ & & \\
\hline \multirow{4}{*}{$\begin{array}{l}\text { M anutenção da Vigilância } \\
\text { de saúde } \\
\text { Garantir a continuidade } \\
\text { decuidados }\end{array}$} & Quase sempre/sempre & $34(85 \%)$ & $22(55 \%)$ & 8,571 & 0,003 \\
\hline & Nunca/raramente & $6(15 \%)$ & $18(45 \%)$ & & \\
\hline & Quase sempre/sempre & $33(82 \%)$ & $19(47 \%)$ & 12,579 & 0,000 \\
\hline & Nunca/raramente & $7(18 \%)$ & $21(53 \%)$ & & \\
\hline
\end{tabular}


si; horário e número de visitas; uso de objectos pessoais; forma de comunicar com a família e amigos; manutenção da vigilância de saúdeeforma de garantir a continuidade dos cuidados no domicílio, existe uma relação entre os grupos estudados, confirmando-se que os doentes do grupo submetido a um programa de informação obtêm mais informações do que os doentes do grupo quenão foi submetido a um programa de informação.

Já no que diz respei to a nome do médico responsável por si e data provável da alta clínica, não se confirmou a relação entre os grupos estudados, atendendo ao facto de não se observarem diferenças quanto à obtenção de informações entre os doentes do grupo submetido a um programa de informação e os doentes do grupo não submetido a um programa de informação.

Relação entre a transmissão e a obtenção de informações

De acordo com a Tabela 3, verifica-se a relação existente entrea transmissão deinformações por parte dos enfermeiros ea obtenção das mesmas informações por parte dos doentes. Desta forma, no que toca à hipótese de investigação "existe desfasamento entre enfermeiros e doentes no que respeita à informação transmitida e recebida", entre enfermei ros e doentes do grupo submetido a programa de informação e entre enfermeiros e doentes do grupo não submetido a programa deinformação, verificou-se (com um nível de confiança de $95 \%$ e um grau de liberdade) que esse desfasamento existe somente no grupo não submetido a programa de informação e relativamente aos itens terapêutica; meios de diagnóstico; nome do enfermeiro; horário e número de visitas; uso de objectos pessoais; manutenção da vigilância de saúde e garantir a continuidade de cuidados no domicílio.

N estes casos, não houve correspondência entre as informações que os enfermeiros disseram ter transmitido e aquelas que realmente os doentes disseram ter obtido.

Tabela 2. Distribuição das populações no que respeita à obtenção de informações.

\begin{tabular}{|c|c|c|c|c|c|}
\hline $\begin{array}{l}\text { No que } \\
\text { respeita a: }\end{array}$ & $\begin{array}{l}\text { Obtenção de } \\
\text { informações }\end{array}$ & $\begin{array}{l}\text { Grupo submetido } \\
\text { a programa de } \\
\text { informação }\end{array}$ & $\begin{array}{c}\text { Grupo não submetido } \\
\text { a programa de } \\
\text { informação }\end{array}$ & $0 \chi^{2}$ & $P$ \\
\hline \multirow[t]{2}{*}{ Terapêutica } & Quase sempre/sempre & $72(90 \%)$ & $14(17 \%)$ & 84,576 & 0,000 \\
\hline & Nunca/raramente & $8(10 \%)$ & $66(83 \%)$ & & \\
\hline \multirow[t]{2}{*}{ Tratamentos } & Quase sempre/sempre & $71(89 \%)$ & $32(40 \%)$ & 41,451 & 0,000 \\
\hline & Nunca/raramente & $9(11 \%)$ & $48(60 \%)$ & & \\
\hline \multirow[t]{2}{*}{ M eios de diagnóstico } & Quase sempre/sempre & $55(69 \%)$ & $11(14 \%)$ & 49,929 & 0,000 \\
\hline & Nunca/raramente & $25(31 \%)$ & $69(86 \%)$ & & \\
\hline \multirow[t]{2}{*}{ Nome do enfermeiro } & Quase sempre/sempre & $73(91 \%)$ & $7(9 \%)$ & 108,900 & 0,000 \\
\hline & Nunca/raramente & $7(9 \%)$ & $73(91 \%)$ & & \\
\hline \multirow[t]{2}{*}{ Nome do médico } & Quase sempre/sempre & $72(90 \%)$ & $67(84 \%)$ & 1,370 & 0,000 \\
\hline & Nunca/raramente & $8(10 \%)$ & $13(16 \%)$ & & \\
\hline \multirow[t]{2}{*}{ Horário e número de visitas } & Quase sempre/sempre & $73(91 \%)$ & $12(15 \%)$ & 93,390 & 0,242 \\
\hline & Nunca/raramente & $7(9 \%)$ & $68(85 \%)$ & & \\
\hline \multirow[t]{2}{*}{ Uso de objectos pessoais } & Quase sempre/sempre & $67(84 \%)$ & $8(10 \%)$ & 87,366 & 0,000 \\
\hline & Nunca/raramente & $13(16 \%)$ & $72(90 \%)$ & & \\
\hline \multirow{2}{*}{$\begin{array}{l}\text { Comunicar com a família } \\
\text { e amigos }\end{array}$} & Quase sempre/sempre & $71(89 \%)$ & $48(60 \%)$ & 17,348 & 0,000 \\
\hline & Nunca/raramente & $9(11 \%)$ & $32(40 \%)$ & & \\
\hline \multirow[t]{2}{*}{ Data provável da alta clínica } & Quase sempre/sempre & $36(45 \%)$ & $26(32 \%)$ & 2,633 & 0,105 \\
\hline & Nunca/raramente & $44(55 \%)$ & $54(68 \%)$ & & \\
\hline \multirow{4}{*}{$\begin{array}{l}\text { M anutenção da Vigilância } \\
\text { de saúde } \\
\text { Garantir a continuidade } \\
\text { decuidados }\end{array}$} & Quase sempre/sempre & $71(89 \%)$ & $15(19 \%)$ & 78,843 & 0,000 \\
\hline & Nunca/raramente & $9(11 \%)$ & $65(81 \%)$ & & \\
\hline & Quase sempre/sempre & $72(90 \%)$ & $11(14 \%)$ & 93,156 & 0,000 \\
\hline & Nunca/raramente & $8(10 \%)$ & $69(86 \%)$ & & \\
\hline
\end{tabular}


Tabela 3. Relação entre a transmissão de informações (por parte dos enfermeiros) e a obtenção de informações (por parte dos doentes).

\begin{tabular}{|c|c|c|c|c|c|c|c|}
\hline \multirow[t]{2}{*}{$\begin{array}{l}\text { No que } \\
\text { respeita a: }\end{array}$} & \multirow[t]{2}{*}{$\begin{array}{l}\text { Transmissão/O btenção } \\
\text { De informações }\end{array}$} & \multicolumn{2}{|c|}{$\begin{array}{l}\text { Grupo submetido a } \\
\text { programa de } \\
\text { informação }\end{array}$} & \multirow{2}{*}{$\begin{array}{l}\text { significância } \\
\text { s }\end{array}$} & \multicolumn{2}{|c|}{$\begin{array}{l}\text { Grupo não submetido } \\
\text { a programa de } \\
\text { informação }\end{array}$} & \multirow[t]{2}{*}{ significância } \\
\hline & & $\begin{array}{r}\text { Enfermeiros } \\
\text { (transmissão) }\end{array}$ & $\begin{array}{r}\text { D oentes } \\
\text { (obtenção) }\end{array}$ & & $\begin{array}{l}\text { Enfermeiros } \\
\text { (transmissão) }\end{array}$ & $\begin{array}{r}\text { Doentes } \\
\text { (obtenção) }\end{array}$ & \\
\hline rapêutica & Quase sem & 32 & $72(90 \%)$ & $=2,308$ & \%) & $14(17 \%)$ & $2=45$ \\
\hline Tratamentos & $\begin{array}{l}\text { Nunce } \\
\text { Quase } \\
\text { Nunce }\end{array}$ & $\begin{array}{r}34 \\
6\end{array}$ & $\begin{array}{r}8(10 \%) \\
71(89 \%) \\
9(11 \%)\end{array}$ & & & 321 & $\begin{array}{l}290 \\
, 070\end{array}$ \\
\hline M eios de diagnóstico & $\begin{array}{l}\text { Quase sempre/sempre } \\
\text { Nunca/raramente }\end{array}$ & & $\begin{array}{l}55(69 \%) \\
25(31 \%)\end{array}$ & $\begin{aligned} \chi^{2} & =2,578 \\
p & =0,108\end{aligned}$ & $\begin{array}{l}18(49 \%) \\
22(55 \%)\end{array}$ & $\begin{array}{l}11(14 \%) \\
69(86 \%)\end{array}$ & $\begin{array}{r}\chi^{2}=14,210 \\
p=0,000\end{array}$ \\
\hline Nome do enfermeiro & $\begin{array}{l}\text { Quase sempre/sempre } \\
\text { Nunca/raramente }\end{array}$ & $\begin{array}{r}34(85 \%) \\
6(15 \%)\end{array}$ & $\begin{array}{r}73(91 \%) \\
7(9 \%)\end{array}$ & $\begin{aligned} \chi^{2} & =1,078 \\
p & =0,299\end{aligned}$ & $\begin{array}{l}19(47 \%) \\
21(53 \%)\end{array}$ & $\begin{array}{r}7(9 \%) \\
73(91 \%)\end{array}$ & $\begin{array}{r}\chi^{2}=23,592 \\
p=0,000\end{array}$ \\
\hline Nome do médico & $\begin{array}{l}\text { Quase sempre/sempre } \\
\text { Nunca/raramente }\end{array}$ & $\begin{array}{r}33(82 \%) \\
7(18 \%)\end{array}$ & $\begin{array}{r}72(90 \%) \\
8(10 \%)\end{array}$ & $\begin{aligned} \chi^{2} & =1,371 \\
p & =0,242\end{aligned}$ & $\begin{array}{l}30(75 \%) \\
10(25 \%)\end{array}$ & $\begin{array}{l}67(84 \%) \\
13(16 \%)\end{array}$ & $\begin{aligned} \chi^{2} & =1,318 \\
p & =0,251\end{aligned}$ \\
\hline $\begin{array}{l}\text { Horário e número de } \\
\text { isitas }\end{array}$ & $\begin{array}{l}\text { Quase sempre/sempre } \\
\text { Nunca/raramente }\end{array}$ & $\begin{array}{r}34(85 \%) \\
6(15 \%)\end{array}$ & $\begin{array}{r}73(91 \%) \\
7(9 \%)\end{array}$ & $\begin{aligned} \chi^{2} & =1,078 \\
p & =0,299\end{aligned}$ & $\begin{array}{l}17(43 \%) \\
23(57 \%)\end{array}$ & $\begin{array}{l}12(15 \%) \\
68(85 \%)\end{array}$ & $\begin{array}{r}\chi^{2}=11,004 \\
p=0,001\end{array}$ \\
\hline $\begin{array}{l}\text { Uso de objectos } \\
\text { pessoais }\end{array}$ & $\begin{array}{l}\text { Quase sempre/sempre } \\
\text { Nunca/raramente }\end{array}$ & $\begin{array}{r}33(82 \%) \\
7(18 \%)\end{array}$ & $\begin{array}{l}67(84 \%) \\
13(16 \%)\end{array}$ & $\begin{aligned} \chi^{2} & =0,030 \\
p & =0,862\end{aligned}$ & $\begin{array}{l}22(18 \%) \\
18(45 \%)\end{array}$ & $\begin{array}{r}8(10 \%) \\
72(90 \%)\end{array}$ & $\begin{array}{r}\chi^{2}=28,800 \\
p=0,000\end{array}$ \\
\hline $\begin{array}{l}\text { Comunicar com a } \\
\text { família e amigos }\end{array}$ & $\begin{array}{l}\text { Quase sempre/sempre } \\
\text { Nunca/raramente }\end{array}$ & $\begin{array}{r}34(85 \%) \\
6(15 \%)\end{array}$ & $\begin{array}{r}71(89 \%) \\
9(11 \%)\end{array}$ & $\begin{aligned} \chi^{2} & =0,343 \\
p & =0,558\end{aligned}$ & $\begin{array}{l}22(55 \%) \\
18(45 \%)\end{array}$ & $\begin{array}{l}48(60 \%) \\
32(40 \%)\end{array}$ & $\begin{aligned} \chi^{2} & =0,274 \\
p & =0,600\end{aligned}$ \\
\hline ata provável da alta & Quase sempre/sempre & $18(45 \%)$ & $36(45 \%)$ & $\chi^{2}=0,000$ & $15(37 \%)$ & $26(32 \%)$ & $\chi^{2}=0,296$ \\
\hline & & & & & & & \\
\hline anutenção da & Quase sempre/sempre & $34(85 \%)$ & $71(89 \%)$ & $\chi^{2}=0,343$ & $22(55 \%)$ & $15(19 \%)$ & $\chi^{2}=16,431$ \\
\hline & & & & & $18(45 \%)$ & $65(81 \%)$ & $p=0$ \\
\hline de saúde & Quase sempre/sempre & $34(85 \%)$ & $72(90 \%)$ & $\chi^{2}=0,647$ & $19(47 \%)$ & $11(14 \%)$ & $\chi^{2}=16,200$ \\
\hline $\begin{array}{l}\text { Garantir a continuidade } \\
\text { decuidados }\end{array}$ & e Nunca/raramente & $6(15 \%)$ & $8(10 \%)$ & $p=0,421$ & $21(53 \%)$ & $69(86 \%)$ & $p=0,000$ \\
\hline
\end{tabular}

\section{Conclusões}

Com um programa de suportee informação instituído num hospital, o doente compreenderia a necessidade de manifestar todas as suas dúvidas, receios ou queixas, de modo a possibilitar a ajuda do enfermeiro. Além da resposta às perguntas e dúvidas apresentadas, o enfermeiro facultará informação diversa sobre 0 ambiente hospitalar, as pessoas que intervirão no seu tratamento, detal hes da terapêutica e exames dediagnóstico a efectuar, intervenção cirúrgica, existência da dor, a hipótese de ocorrência de complicações pós-operatórias e a vantagem da sua participação em todo o processo de internamento.

Seria útil e desejável que todas as instituições hospital ares conseguissem implementar nas suas unidades programas de suporte e informação.

Creio ser igualmente pertinente fazer algumas sugestões no domínio da formação inicial dos enfermeiros e da prática hospitalar, de tal forma que todos possam reflectir e encontrar a melhor maneira de contribuir para a melhoria da imagem social da profissão de enfermagem, melhorar a qualidade dos cuidados prestados ao doente, econtribuir para a tão desejada humanização dos hospitais.

Quer para os docentes, quer para os discentes das escolas superiores de enfermagem, seria útil a criação de espaços de reflexão e debate sobreal guns aspectosimportantes, tais como a carta dos direitos e deveres dos doentes e o código deontológico profissional, no sentido de se contribuir para um melhor desenvolvimento sociomoral dos alunos e que pudesse levar a uma maior humanização dos cuidados.

Na prática hospitalar, deveriam também ser criados espaços de reflexão e debate dos assuntos acima referenciados, assim como de algumas situações vivenciadas, no sentido deos enfermei- 
ros desenvolverem capacidades para lidar com as múltiplas situações dilemáticas com que por vezes se deparam. D everia fomentar-sea existência de contactos mais próximos dos enfermeiros, não só com o doente, mas também com os seus familiares e amigos, informando e esclarecendo dúvidas que porventura existam e garantindo a continuidade dos cuidados, quando os doentes tiverem alta e deles necessitarem.

\section{Referências}

1. Watzlawick P, Beavin JH, Jackson DD. Pragmática da Comunicação Humana. São Paulo: Cultrix; 1967.

2. Dias R. O valor da Informação nos valores da ciência médica. Análise Psicológica 1994; 12:349-353.

3. Dias R. A esmeralda perdida: a informação ao doente com cancro da mama. 1 a ed. Lisboa: Instituto Superior de Psicologia Aplicada; 1997.

4. Messner R. What Patients Really Want From Their Nurses. Am J Nurs 1993; 93(8):38-41.

5. Ley P. Giving information to patients. In: Eiser JR, editor. Social psychology and behavioral medicine. New York: John Wiley \& Sons; 1985.

6. Dupont C. Coping mechanism and anxiety in advanced level cancerous patients related to hospitalization awareness of diagnosis. Proceeding ECCO 1987; 4.

7. Szmajke K, Hans O, Kaiser A. Psychosocial problem in leukemia: influence of the knowlegde about the disease on anxiety level and familial interaction. Proceeding ECCO 1987; 4.

8. Durà E. El dilema de informar al paciente de cancer. Valencia: Nau Libres; 1990.

9. Mártires A. A pessoa em situação de internamento hospitalar e as suas percepções sobre os cuidados de enfermagem [dissertação]. Porto: Instituto de Ciências Biomédicas Abel Salazar, Universidade do Porto; 1998.

10. Rodrigues V. A complexidade dos problemas humanos no Hospital : Vivências e reflexões. Vila Real: Sodivir, Edições do Norte; 1999.

11. Pio Abreu J. 0 espaço e o tempo nos signos. Revista Interacções 1997; 5:43-64.

12. Levinson P. A Arma Suave; História Natural e futuro da Revolução da informação. Lisboa: Editorial Bizânico; 1997.

13. Corney R. O Desenvolvimento das perícias de comunicação e de aconselhamento em medicina. Lisboa: Climepsi Editores; 1991.

14. Polit D, Hungler B. Fundamentos de pesquisa em Enfermagem. 3a ed. Lisboa: Artes M édicas; 1995.

15. Lakatos E, Marconi M. Técnicas de pesquisa. 3a ed. São Paulo: Atlas; 1996.

16. Reis E, Melo P, Andrade R, Calapez T. Estatística Aplicada. Vol. 2. Lisboa: Edições Silabo; 1997. 